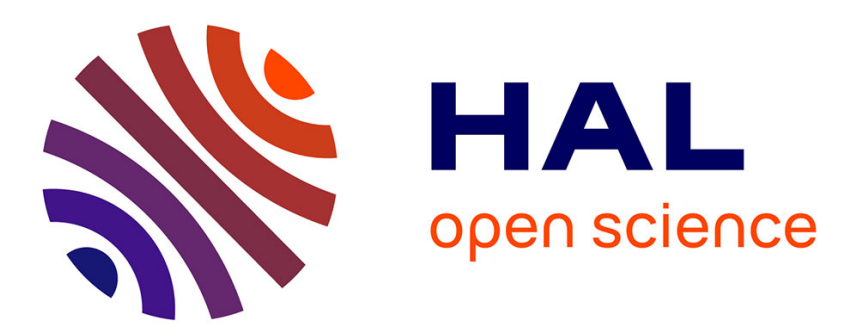

\title{
Fissuring and Fragmentation Removal During Sol-Gel Catalytic Materials Synthesis: An Experimental Design Approach
}

\author{
C. Raillard, Valérie Hequet, P. Le Cloirec, J. Legrand
}

\section{- To cite this version:}

C. Raillard, Valérie Hequet, P. Le Cloirec, J. Legrand. Fissuring and Fragmentation Removal During Sol-Gel Catalytic Materials Synthesis: An Experimental Design Approach. Journal of Sol-Gel Science and Technology, 2005, 34 (1), pp.5-14. 10.1007/s10971-005-1257-9 . hal-02362982

\section{HAL Id: hal-02362982 \\ https://hal.science/hal-02362982}

Submitted on 18 Nov 2019

HAL is a multi-disciplinary open access archive for the deposit and dissemination of scientific research documents, whether they are published or not. The documents may come from teaching and research institutions in France or abroad, or from public or private research centers.
L'archive ouverte pluridisciplinaire HAL, est destinée au dépôt et à la diffusion de documents scientifiques de niveau recherche, publiés ou non, émanant des établissements d'enseignement et de recherche français ou étrangers, des laboratoires publics ou privés. 


\title{
Fissuring and Fragmentation Removal During Sol-Gel Catalytic Materials Synthesis: An Experimental Design Approach
}

\author{
C. RAILLARD, V. HÉQUET* AND P. LE CLOIREC \\ Ecole des Mines de Nantes, GEPEA UMR CNRS 6144, 4 rue Alfred Kastler, BP 20722, \\ 44307 Nantes Cedex 3, France \\ Valerie.Hequet@emn.fr \\ J. LEGRAND \\ Université de Nantes, GEPEA, UMR CNRS 6144, CRTT, Boulevard de l'Université, BP 406, \\ 44602 Saint-Nazaire Cedex, France
}

Received January 16, 2003; Accepted October 22, 2004

\begin{abstract}
Statistical designs were used to investigate the effects of various processing conditions on the fissuring and/or fragmentation of sol-gel catalytic materials. Three types of sol-gel materials were studied: $\mathrm{SiO}_{2}, \mathrm{TiO}_{2}$ doped $\mathrm{SiO}_{2}$ and $\mathrm{CeO}_{2}$-doped $\mathrm{SiO}_{2}$. Five processing variables were investigated: the quantity of water included in the sol-gel preparation, the amount of $\mathrm{TiO}_{2}$ or $\mathrm{CeO}_{2}$ precursors, the mixing time, the gelation time and the influence of treatment in an oven at $40^{\circ} \mathrm{C}$ prior to the heating treatment (pre-heating time). Processing variables were set at high and low limits in three different $2^{4}$ full-factorial designs. As notable results, the water content appeared to be a critical processing variable in every studied factorial designs. Pre-heating time was also significant for $\mathrm{SiO}_{2}$ gels. Finally the amount of $\mathrm{CeO}_{2}$ precursor and the gelation time were found to be influential for the synthesis of non-cracked $\mathrm{CeO}_{2}$-doped $\mathrm{SiO}_{2}$ sol-gel monoliths.
\end{abstract}

Keywords: sol-gel catalysts, cracking, factorial design, $\mathrm{TiO}_{2}, \mathrm{SiO}_{2}, \mathrm{CeO}_{2}$

\section{Introduction}

Photocatalytic oxidation is more and more studied for applications in environmental processes dealing with water and air treatment. Works particularly focus on the development of new efficient photocatalysts. Metallic oxides and mixed oxides are of great interest as photocatalytic materials that can be activated by visible or near-UV light. Sol-gel techniques are widely used for the preparation of mixed oxides having properties useful in catalysis [1] and glass materials applications [2]. Metallic oxides such as $\mathrm{CeO}_{2}$ and $\mathrm{TiO}_{2}$ were found to be particularly attractive because of their catalytic [3-5] and photocatalytic properties [6-10]. $\mathrm{TiO}_{2}$ and

\footnotetext{
*To whom all correspondence should be addressed.
}

$\mathrm{CeO}_{2}$ can be added in small amounts or mixed with some other oxides in order to improve surface characteristics (surface area and porosity), thermal stability and mechanical resistance [1]. Previous works have been carried out on $\mathrm{TiO}_{2}$ - or $\mathrm{CeO}_{2}$-doped $\mathrm{SiO}_{2}$ dealing with their structural characteristics (surface area, pore size and volume, crystalline structure and crystallites size) [4, 11-15], their specific properties (electronic, electrochemical, optical and spectroscopic properties) [12, 16-19] and their catalytic activity [1, 20]. For instance, cerium dioxide acts as an oxygen storage agent and doping it into a silica framework under certain conditions increases the amount of available oxygen leading to the enhancement of the catalytic activity $[3,4]$. Reactions such as the reduction of nitrogen oxides by carbon monoxide, oxidation of volatile organic 
compounds as well as carbon monoxide oxidation can be catalyzed by $\mathrm{CeO}_{2}$-doped $\mathrm{SiO}_{2}$ materials [3]. Recent results on applications of sol-gel titania-silica materials as photocatalysts, acid catalysts and oxidation catalysts have been reviewed by Gao et al. [19]. The following catalyzed reactions were listed: photodecomposition of chlorinated phenols, photoreduction of $\mathrm{CO}_{2}$, photodecomposition of rhodamine- $6 \mathrm{G}$ and phenol, complete photocatalytic oxidation of $\mathrm{C}_{2} \mathrm{H}_{4}$, isomerization of 1-butene and methyloxane to propanal, methanol dehydration, oxidation of alkenes and alcohols with hydrogen peroxide, decane hydrofissuring, propanol dehydration, ammoxidation of cyclohexanone, etc [1, 14, 19].

One major problem happening during sol-gel synthesis is fissuring and/or fragmentation. Fragmentation refers to materials breaking in several pieces, whereas fissuring leads to a defect in sol-gel materials, but not to their breaking. The surface tension of the liquid remaining in the pores stresses the silica network during the aging and drying steps of the synthesis. The resulting forces can produce severe fissuring and/or fragmentation inside the sol-gel materials [2]. Control over fissuring and fragmentation represents a major objective for the improvement of sol-gel processing.

In the present work we aim to synthesize monolithic sol-gel materials of $\mathrm{SiO}_{2}, \mathrm{TiO}_{2}$ - doped $\mathrm{SiO}_{2}$ and $\mathrm{CeO}_{2}$ doped $\mathrm{SiO}_{2}$ showing no fragments and no fissures in order to produce photocatalysts usable in environmental processes dealing with water and air treatment. The materials would have to be roughly $1.0 \times 0.5 \times 0.5 \mathrm{~cm}^{3}$ in dimension in only one piece and showing no visible defects. In this perspective, we defined several parameters involved in sol-gel synthesis and applied factorial designs to assess the influence of these parameters on the fissuring and fragmentation of monolithic sol-gel materials of $\mathrm{SiO}_{2}, \mathrm{TiO}_{2} / \mathrm{SiO}_{2}$ and $\mathrm{CeO}_{2} / \mathrm{SiO}_{2}$.

\section{Experimental Procedures}

\subsection{Sol-Gel Preparation}

Sol-gel materials were composed of a siliceous matrix only $\left(\mathrm{SiO}_{2}\right)$ or doped with titanium or cerium dioxides $\left(\mathrm{TiO}_{2} / \mathrm{SiO}_{2}\right.$ and $\left.\mathrm{CeO}_{2} / \mathrm{SiO}_{2}\right)$. Chemicals used in the preparation were tetramethylorthosilicate (TMOS, $\left.\mathrm{Si}\left(\mathrm{OCH}_{3}\right)_{4}, 98 \%\right)$ as precursor for silica, titanium (IV) isopropoxide (TTIP, Ti[OCH $\left.\left(\mathrm{CH}_{3}\right)_{2}\right]_{4}, 97 \%$ ) as precursor for $\mathrm{TiO}_{2}$ and ammonium cerium (IV) nitrate (Am$\left.\mathrm{CeNi},\left(\mathrm{NH}_{4}\right)_{2} \mathrm{Ce}\left(\mathrm{NO}_{3}\right)_{6},>99,99 \%\right)$ as precursor for
$\mathrm{CeO}_{2}$ supplied by Aldrich Chemicals and used without further treatment. Ultra-pure water from a MilliQ (Millipore) system was used for hydrolysis and 2propanol was used as solvent. Sol-gel materials were prepared according to the synthesis of vanadia-silica sol-gel carried out by Stiegman et al. and Curran et al. $[21,22]$. The sol-gel syntheses were defined to be as simple as possible, so no catalyst was introduced in the preparation.

Hydrolysis and condensation of TMOS can be described by the following reaction sequence [6]:

$$
\begin{aligned}
& \mathrm{Si}\left(\mathrm{OCH}_{3}\right)_{4}+\mathrm{H}_{2} \mathrm{O} \rightarrow \mathrm{Si}\left(\mathrm{OCH}_{3}\right)_{3}(\mathrm{OH})+\mathrm{CH}_{3} \mathrm{OH} \\
& \mathrm{Si}\left(\mathrm{OCH}_{3}\right)_{3}(\mathrm{OH})+\mathrm{Si}\left(\mathrm{OCH}_{3}\right)_{4} \\
& \quad \rightarrow\left(\mathrm{OCH}_{3}\right)_{3} \mathrm{Si}-\mathrm{O}-\mathrm{Si}\left(\mathrm{OCH}_{3}\right)_{3}+\mathrm{CH}_{3} \mathrm{OH} \\
& \quad \mathrm{Si}\left(\mathrm{OCH}_{3}\right)_{3}(\mathrm{OH})+\mathrm{Si}\left(\mathrm{OCH}_{3}\right)_{3}(\mathrm{OH}) \\
& \quad \rightarrow\left(\mathrm{OCH}_{3}\right)_{3} \mathrm{Si}-\mathrm{O}-\mathrm{Si}\left(\mathrm{OCH}_{3}\right)_{3}+\mathrm{H}_{2} \mathrm{O}
\end{aligned}
$$

In case of $\mathrm{TiO}_{2} / \mathrm{SiO}_{2}$ and $\mathrm{CeO}_{2} / \mathrm{SiO}_{2}$ materials, titanium or cerium precursors were mixed with the silica precursor during the synthesis so that $\mathrm{Ti}$ and $\mathrm{Ce}$ atoms were incorporated in the silica network.

For each synthesized material, components were mixed together and stirred ultrasonically at ambient temperature $\left(20 \pm 1^{\circ} \mathrm{C}\right)$. The solution was then poured in $3-\mathrm{mL}$ polystyrene cuvettes which were sealed and allowed to gel. Gelation time corresponded to the period when the initial solution changed from a liquid to a gel and lasted until the drying step was initiated. After gelation, the seals were punctured to initiate the drying step. The materials were allowed to dry for approximately two months. After the drying period, a heat treatment was carried out in a tubular furnace (Thermolyne F79500) with a temperature program ranging from $40^{\circ} \mathrm{C}$ to $500^{\circ} \mathrm{C}$ under air flow fixed at $100 \mathrm{~mL} \cdot \mathrm{min}^{-1}$.

\subsection{The Factorial Design Approach [23-28]}

Experiments are usually performed to investigate the effects of some variables on a physical quantity. The aim is generally to find a functional dependence between this physical quantity and several variables or parameters $X_{j}(j=1, \ldots, k)$ involved in the experiments. A traditional method to do so is to conduct a series of experiments by varying only one $X_{j}$, keeping the others fixed to a reference value. The procedure is then repeated for each $X_{j}$ in several points (3,5 or more) to obtain a satisfactory precision. This approach is called the one-parameter-at-a-time approach and appears to 
be well adapted when a really deep inspection is needed and only a few variables are considered [23]. This approach is no longer relevant when dealing with more variables or parameters, because of the necessity of carrying out a huge number of experiments and a lack of information about the possible interactions among the variables [24]. A way to assess the effects of the parameters and their interactions can be to perform a factorial design. The latter consists in experimenting with every combination. That is to say to change variables together instead of one at a time. This approach ensures the widest information with the lowest number of experiments [24]. For instance, considering designs with a fixed number of $k$ variables $(k \geq 2)$, each at two different levels, a total of $2^{k}$ experiments is required by the factorial design to test every combination [25].

In the present study three $2^{4}$ full-factorial designs were performed for factor screening, in order to select and optimize the process variables and exclude the insignificant ones concerning the synthesis of noncracked (neither fragmented nor fissured) sol-gel materials. The first one focused on $\mathrm{SiO}_{2}$ sol-gel synthesis, the second one was carried out for studying $\mathrm{TiO}_{2} / \mathrm{SiO}_{2}$ and the last one dealt with $\mathrm{CeO}_{2} / \mathrm{SiO}_{2}$ sol-gel materials. In a $2^{4}$ factorial design, there are 16 runs which are organized in a design matrix (Tables 1 and 2) [29-31]. Runs were randomized in order to avoid systematic errors.

\subsection{Process Variables}

The influence of five process variables was investigated in this study. Each variable was fixed at a low and a high level. The variables and their different levels are given in Tables 1 and 2.

During the preparation ultra-pure water was added at a Water:TMOS molar ratio $\left(X_{1}\right)$ of either 3.8 or 10 . Titanium isopropoxide and ammonium cerium nitrate were introduced into the preparation using a $\mathrm{TiO}_{2}$ :TMOS or $\mathrm{CeO}_{2}$ :TMOS molar ratio $\left(X_{2}\right)$ of either 0.005 or $0.1 \%$. Both first and second mixing periods took place at ambient temperature in an ultrasonic bath. The first one lasted $5 \mathrm{~min}$ in every preparation whereas the second one, recorded as mixing time $\left(X_{3}\right)$ in the process variables, was either 30 or 60 min long. Gelation time $\left(X_{4}\right)$ corresponded to the period when the initial solution changed from a liquid to a gel and lasted until the drying step was initiated. It could also be named aging time and is the period when the condensation of $\mathrm{Si}-\mathrm{OH}$ groups can be observed [2]. Gelation time was tested at
Table 1. Design matrix for $\mathrm{SiO}_{2} 2^{4}$ factorial experiments.

\begin{tabular}{|c|c|c|c|c|c|}
\hline Run & $\mathrm{X}_{1}$ & $\mathrm{X}_{3}$ & $\mathrm{X}_{4}$ & $\mathrm{X}_{5}$ & Responses \\
\hline 1 & - & - & - & - & 7 \\
\hline 2 & + & - & - & - & 2 \\
\hline 3 & - & + & - & - & 7 \\
\hline 4 & + & + & - & - & 7 \\
\hline 5 & - & - & + & - & 9 \\
\hline 6 & + & - & + & - & 3 \\
\hline 7 & - & + & + & - & 3 \\
\hline 8 & + & + & + & - & 2 \\
\hline 9 & - & - & - & + & 7 \\
\hline 10 & + & - & - & + & 2 \\
\hline 11 & - & + & - & + & 10 \\
\hline 12 & + & + & - & + & 6 \\
\hline 13 & - & - & + & + & 9 \\
\hline 14 & + & - & + & + & 7 \\
\hline 15 & - & + & + & + & 7 \\
\hline 16 & + & + & + & + & 9 \\
\hline$X_{i}$ & \multicolumn{2}{|c|}{ Variable } & Unit & - Limit & + Limit \\
\hline$X_{1}$ & \multicolumn{2}{|c|}{ Water:TMOS ratio } & $\mathrm{mol} / \mathrm{mol}$ & 3.8 & 10 \\
\hline$X_{3}$ & \multicolumn{2}{|c|}{ Mixing time } & minutes & 30 & 60 \\
\hline$X_{4}$ & \multicolumn{2}{|c|}{ Gelation time } & weeks & 1 & 3 \\
\hline$X_{5}$ & \multicolumn{2}{|c|}{ Pre-heating time } & days & 0 & 4 \\
\hline
\end{tabular}

two levels: 1 or 3 weeks. For silica sol-gel only, a fifth process variable was studied. It occurred at the end of the preparation process just before the heat treatment and corresponded to a treatment of unsealed sol-gel materials in an oven at $40^{\circ} \mathrm{C}$. This parameter, called pre-heating time $\left(X_{5}\right)$, was set at two levels as well: 0 or 4 days. This variable was suppressed in $\mathrm{TiO}_{2} / \mathrm{SiO}_{2}$ and $\mathrm{CeO}_{2} / \mathrm{SiO}_{2}$ factorial designs because, although its influence was significant, it showed a negative effect on fissuring removal. The number of fragments and fissures was increased when pre-heating time was set at its upper limit (4 days). For $\mathrm{TiO}_{2} / \mathrm{SiO}_{2}$ and $\mathrm{CeO}_{2} / \mathrm{SiO}_{2}$ factorial designs this variable was fixed at its lower limit ( 0 day) and replaced by the parameter $\mathrm{X}_{2}$. This permitted the study of $2^{4}$ factorial designs for $\mathrm{TiO}_{2} / \mathrm{SiO}_{2}$ and $\mathrm{CeO}_{2} / \mathrm{SiO}_{2}$ materials.

\subsection{The Response: Sol-Gel Materials Characterization}

The characterization of sol-gel materials aimed to determine a response for each sample in order to analyze 
Table 2. Design matrix for $\mathrm{TiO}_{2} / \mathrm{SiO}_{2}$ and $\mathrm{CeO}_{2} / \mathrm{SiO}_{2} 2^{4}$ factorial experiments.

\begin{tabular}{|c|c|c|c|c|c|c|c|}
\hline Run & $X_{1}$ & $X_{2}$ & $X_{3}$ & $X_{4}$ & $\begin{array}{l}\text { Res } \\
\mathrm{TiO}\end{array}$ & & $\begin{array}{l}\text { Responses } \\
\mathrm{CeO}_{2} / \mathrm{SiO}_{2}\end{array}$ \\
\hline 1 & - & - & - & - & & & 2 \\
\hline 2 & + & - & - & - & & & 2 \\
\hline 3 & - & + & - & - & & & 10 \\
\hline 4 & + & + & - & - & & & 4 \\
\hline 5 & - & - & + & - & & & 2 \\
\hline 6 & + & - & + & - & & & 2 \\
\hline 7 & - & + & + & - & & & 7 \\
\hline 8 & + & + & + & - & & & 2 \\
\hline 9 & - & - & - & + & & & 3 \\
\hline 10 & + & - & - & + & & & 2 \\
\hline 11 & - & + & - & + & & & 10 \\
\hline 12 & + & + & - & + & & & 7 \\
\hline 13 & - & - & + & + & & & 3 \\
\hline 14 & + & - & + & + & & & 2 \\
\hline 15 & - & + & + & + & & & 10 \\
\hline 16 & + & + & + & + & & & 7 \\
\hline$X_{i}$ & \multicolumn{3}{|c|}{ Variable } & & Unit & - Limit & + Limit \\
\hline$X_{1}$ & \multirow{2}{*}{\multicolumn{3}{|c|}{$\begin{array}{l}\text { Water:TMOS ratio } \\
\begin{cases}\mathrm{TiO}_{2} & : \text { TMOS ratio } \\
\mathrm{CeO}_{2} & : \text { TMOS ratio }\end{cases} \end{array}$}} & & $\mathrm{ol} / \mathrm{mol}$ & 3.8 & 10 \\
\hline$X_{2}$ & & & & & $\%$ & 0.005 & 0.1 \\
\hline$X_{3}$ & \multicolumn{3}{|c|}{ Mixing time } & & hinutes & 30 & 60 \\
\hline$X_{4}$ & \multicolumn{3}{|c|}{ Gelation time } & & weeks & 1 & 3 \\
\hline
\end{tabular}

experimental designs. The characterization of the solgel materials was performed by visual analysis. This consisted in counting the number of fragments and fissures appearing in sol-gel materials. The number of fragments was defined by the number of pieces in which a material was broken. Fissures did not lead to the breaking of sol-gel materials and were counted in each piece constituting a material. The counting was achieved without any magnification and consequently concerned only fissures visible to the naked eye. Ten categories were defined according to the number of observed fragments and/or fissures (Table 3). Each material was then classified in one category and received a mark between 1 and 10. The operation was repeated 10 times by a jury in order to eliminate any subjectivity from the characterization method. The final mark, corresponding to the response for the analysis of the statistical designs, was estimated with the mean of the marks given by each person. The response was a
Table 3. Categories for the Sol-Gel materials characterization.

\begin{tabular}{lcc}
\hline Category & Observed fractures & Observed cracks \\
\hline 1 & 0 & 0 \\
2 & 0 & 1 or 2 \\
3 & 0 & 3 to 5 \\
4 & 0 & 6 to 10 \\
5 & 0 & 10 to 15 \\
6 & 1 to $4(2$ to 5 pieces $)$ & 0 on the biggest piece \\
7 & 1 to $4(2$ to 5 pieces $)$ & $<10$ on the biggest piece \\
8 & 1 to $4(2$ to 5 pieces $)$ & $>11$ on the biggest piece \\
9 & 0 & $>16$ (not countable) \\
10 & $>5$ & Not countable \\
\hline
\end{tabular}

whole number between 1 and 10 . The lower the number, the better the result in terms of fissuring and/or fragmentation. This method yielded less scattered responses.

Sol-gel materials were also characterized by BET analysis (Micromeretics ASAP 2010) with $\mathrm{N}_{2}$ as adsorptive. Results included the pore size distribution (micropores by Horvath-Kawazoe method, mesopores by BJH adsorption method and adsorption average pore diameter by BET method) and the BET surface area. These results were not used as responses of the experimental designs but were performed to confirm or invalidate some hypotheses on the effects of the main factors and interactions on fissuring and fragmentation of sol-gel materials.

\subsection{Factorial Designs Analysis}

Firstly, experimental responses were used to calculate the main effects of each factor and interactions between process variables. Main effects $(M E)$ of each factor and their interactions of order 2, 3 and 4 were calculated according to the following equations [26-28]:

Main effect for a factor $X_{i}$ :

$$
(M E)_{X_{i}}=\frac{\sum_{j=1}^{16} s_{j} R_{j}}{16}
$$

where $X_{i}$ is the factor ( $i=1$ to 5 ), $s_{j}$ is the plus or minus sign recorded in the design matrix for the factor $X_{i}$ and $R_{j}$ is the response for the run numbered $j$ ( $j=1$ to 16 ).

Second order interaction for factors $X_{i}$ and $X_{k}$ :

$$
\left(I_{2}\right)_{X_{i} X_{k}}=\frac{\sum_{j=1}^{16} s_{j} s^{\prime}{ }_{j} R_{j}}{16}
$$


where $X_{i}$ and $X_{k}$ are the factors $(i=1$ to 4 and $k=2$ to 5 , with $k>i), s_{j}$ is the plus or minus sign recorded in the design matrix for the factor $X_{i}, s^{\prime}{ }_{j}$ is the plus or minus sign for the factor $X_{k}$ and $R_{j}$ is the response for the run $j$ ( $j=1$ to 16 ).

Interactions of order 3 and 4 were calculated in the same way [26-28].

Main effects and interactions were subjected to analysis of variance (ANOVA) in order to understand the magnitude of the influence that each variable and interaction has on the fissuring and/or fragmentation of sol-gel materials. ANOVA consists in comparing two means: one calculated from the sum of squares due to a main effect or an interaction (SSF) and one from the sum of squares due to the total error (SSE) [24, 26, 29].

It was chosen to estimate the total error $\left(e^{2}\right)$ from interactions of third and fourth orders [26]. The latter were supposed to be nil and thus to have no effect on cracking appearance in sol-gel materials. Total error was calculated according to Eq. (6):

Total error:

$$
e^{2}=\sum_{i, k, l}\left(I_{3}\right)_{X_{i} X_{k} X_{l}}^{2}+\sum_{i, k, l, m}\left(I_{4}\right)_{X_{i} X_{k} X_{l} X_{m}}^{2}
$$

In addition the $F$-test (Fisher-Snedecor) was used to determine which process parameters and interactions have a significant effect on the problem. $F$-ratio is calculated using relations defined in Table 4.

The $F$-ratio (the statistical test) is compared to a critical value $\mathcal{F}_{1-\alpha}((k-1) ;(n-k))$ where $1-\alpha$ is the level of significance. Critical values $\mathcal{F}_{1-\alpha}((k-1) ;(n-k))$ are read in the Fisher table; $k-1$ represents the degree of freedom for all main effects and interactions, and $n-k$ is the degree of freedom to calculate the total error. In the present study, the degree of freedom for each factor and interaction of second order is equal to 1 and the degree of freedom for the total error is equal to 5 ( $n=$ number of runs, $k-1=$ number of main effects and second order interactions).

\begin{tabular}{lcccc} 
Table 4. & ANOVA calculations summary. & \\
\hline $\begin{array}{l}\text { Variation } \\
\text { sources }\end{array}$ & $\begin{array}{c}\text { Degree of } \\
\text { freedom }\end{array}$ & $\begin{array}{c}\text { Sum of } \\
\text { squares }\end{array}$ & $\begin{array}{c}\text { Variance }=\text { Mean } \\
\text { of squares }\end{array}$ & $F$ ratio \\
\hline $\begin{array}{l}\text { Main effects } \\
\text { Interactions }\end{array}$ & $k-1$ & SSF & $M S F=\frac{S S F}{k-1}$ & $\frac{M S F}{M S E}$ \\
$\begin{array}{l}\text { Total error } \\
\text { Total }\end{array}$ & $n-k$ & SSE & $M S E=\frac{S S E}{n-k}$ & \\
& $n-1$ & & &
\end{tabular}

\section{Results and Discussion}

\subsection{Responses, Main Effects, Interactions and Experimental Error Calculations}

Using the responses given in Tables 1 and 2, main effects $(M E)$ of each factor and their interactions of 2 , 3 and 4 order were calculated. The results of calculations for the main effects, interactions and total errors of the three studied factorial designs are presented in Table 5.

Plus or minus signs in Table 5 indicate whether main factors and interactions have respectively a negative or a positive effect on cracking of sol-gel materials. A plus sign represents a negative effect, meaning that fissuring and/or fragmentation is increased when variables or interactions pass from the lowest $(-1)$ to the highest $(+1)$ level (Tables 1 and 2). On

Table 5. Main effects, interactions and total error for $\mathrm{SiO}_{2}$, $\mathrm{TiO}_{2} / \mathrm{SiO}_{2}$ and $\mathrm{CeO}_{2} / \mathrm{SiO}_{2}$ factorial designs.

\begin{tabular}{|c|c|c|c|}
\hline & $\begin{array}{c}\mathrm{SiO}_{2} \text { factorial } \\
\text { design }\end{array}$ & $\begin{array}{c}\mathrm{TiO}_{2} / \mathrm{SiO}_{2} \\
\text { factorial design }\end{array}$ & $\begin{array}{c}\mathrm{CeO}_{2} / \mathrm{SiO}_{2} \\
\text { factorial design }\end{array}$ \\
\hline$(\mathrm{ME})_{X 1}$ & -1.3 & -1.4 & -1.2 \\
\hline$(\mathrm{ME})_{X 2}$ & - & 0.9 & 2.4 \\
\hline$(\mathrm{ME})_{X 3}$ & 0.3 & 0.4 & -0.3 \\
\hline$(\mathrm{ME})_{X 4}$ & 0.1 & -0.3 & 0.8 \\
\hline$(\mathrm{ME})_{X 5}$ & 1.1 & - & - \\
\hline$\left(\mathrm{I}_{2}\right)_{X 1 X 2}$ & - & 0.4 & -0.9 \\
\hline$\left(\mathrm{I}_{2}\right)_{X 1 X 3}$ & 0.9 & 0.9 & 0.1 \\
\hline$\left(\mathrm{I}_{2}\right)_{X 1 X 4}$ & 0.4 & -0.8 & 0.2 \\
\hline$\left(\mathrm{I}_{2}\right)_{X 1 X 5}$ & 0.2 & - & - \\
\hline$\left(\mathrm{I}_{2}\right)_{X 2 X 3}$ & - & 0.1 & -0.3 \\
\hline$\left(\mathrm{I}_{2}\right)_{X 2 X 4}$ & - & 0.1 & 0.6 \\
\hline$\left(\mathrm{I}_{2}\right)_{X 3 X 4}$ & -1.2 & 0.3 & 0.3 \\
\hline$\left(\mathrm{I}_{2}\right)_{X 3 \times 5}$ & 0.6 & - & - \\
\hline$\left(\mathrm{I}_{2}\right)_{X 4 X 5}$ & 0.8 & - & - \\
\hline$\left(\mathrm{I}_{3}\right)_{X 1 X 2 X 3}$ & - & 0.6 & 0.1 \\
\hline$\left(\mathrm{I}_{3}\right)_{X 1 X 2 X 4}$ & - & -0.4 & 0.4 \\
\hline$\left(\mathrm{I}_{3}\right)_{X 1 X 3 X 4}$ & 0.2 & -0.7 & -0.1 \\
\hline$\left(\mathrm{I}_{3}\right)_{X 1 X 3 \times 5}$ & -0.3 & - & - \\
\hline$\left(\mathrm{I}_{3}\right)_{X 1 X 4 X 5}$ & 0.7 & - & - \\
\hline$\left(\mathrm{I}_{3}\right)_{X 2 \times 3 \times 4}$ & - & 0.9 & 0.3 \\
\hline$\left(\mathrm{I}_{3}\right)_{X 3 X 4 X 5}$ & 0.3 & - & - \\
\hline$\left(\mathrm{I}_{4}\right)_{X 1 X 2 X 3 X 4}$ & - & -0.1 & -0.1 \\
\hline$\left(\mathrm{I}_{4}\right)_{X 1 X 3 X 4 X 5}$ & 0.2 & - & - \\
\hline$e^{2}$ & 0.7 & 1.9 & 0.3 \\
\hline
\end{tabular}


the contrary, a minus sign means a positive effect on fissuring and/or fragmentation removal from sol-gel monoliths.

\subsection{Analysis of Variance and F-Test}

Results of ANOVA and Fisher-Snedecor tests for the three factorial designs are presented in Figs. 1-3.
In the case of $\mathrm{TiO}_{2} / \mathrm{SiO}_{2}$, the level of significance for the Fisher-Snedecor test was fixed at $90 \%\left(\mathcal{F}_{1-\alpha}\right.$ $(1 ; 5)=4.06)$, otherwise no significant factor or interaction could have been determined. However, for $\mathrm{SiO}_{2}$ and $\mathrm{CeO}_{2} / \mathrm{SiO}_{2}$ statistical designs, the level of significance was fixed at $95 \%\left(\mathcal{F}_{1-\alpha}(1 ; 5)=6.61\right)$. The Fischer critical values are compared with $F$-ratios written on Figs. 1-3 to determine which factors and interactions have a significant effect on fissuring of sol-gel materials.

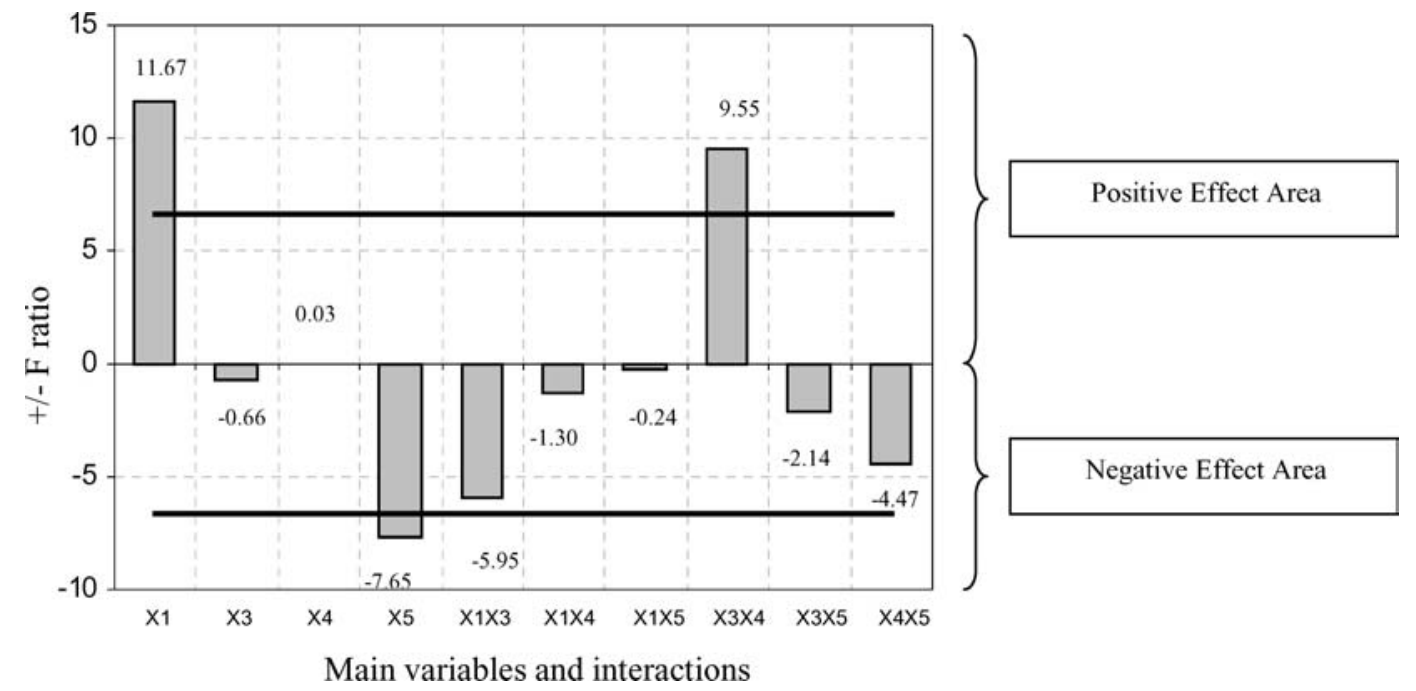

Figure 1. Results of ANOVA and Fischer-Snedecor test for $\mathrm{SiO}_{2}$ factorial design. Unbroken lines represent the Fischer critical value at $95 \%$ of significance.
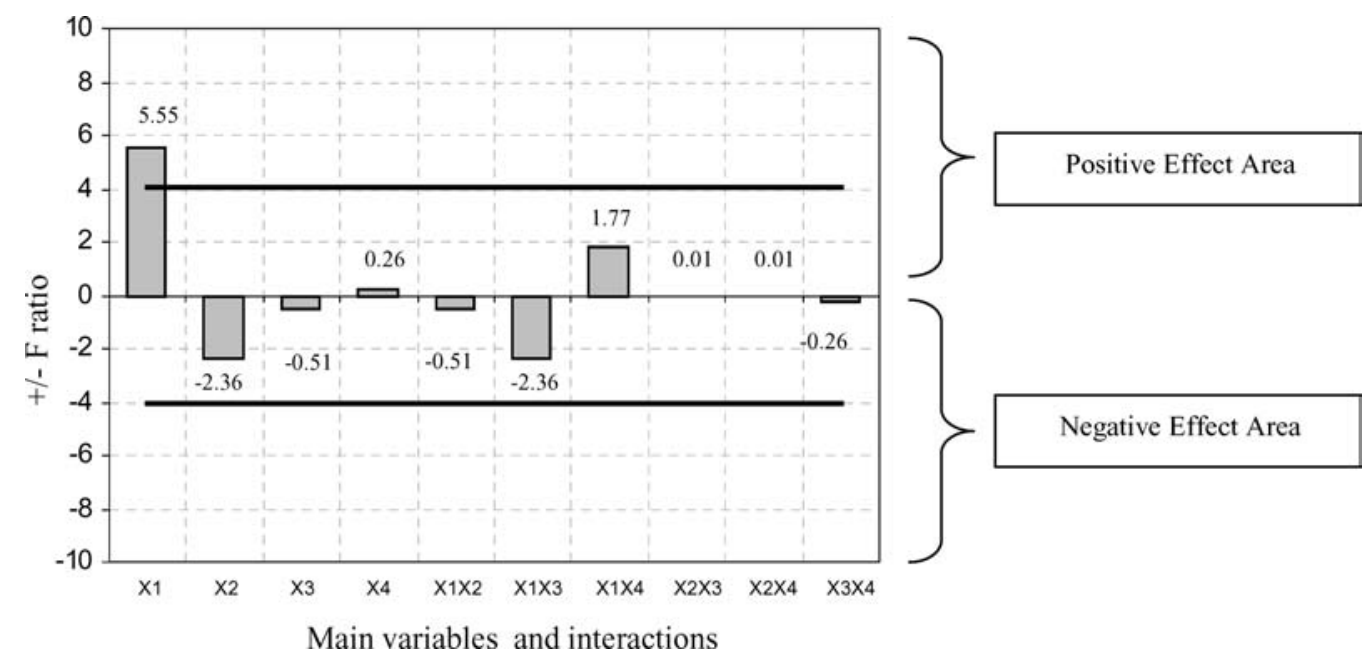

Figure 2. Results of ANOVA and Fischer-Snedecor test for $\mathrm{TiO}_{2} / \mathrm{SiO}_{2}$ factorial design. Unbroken lines represent the Fischer critical value at $90 \%$ of significance. 


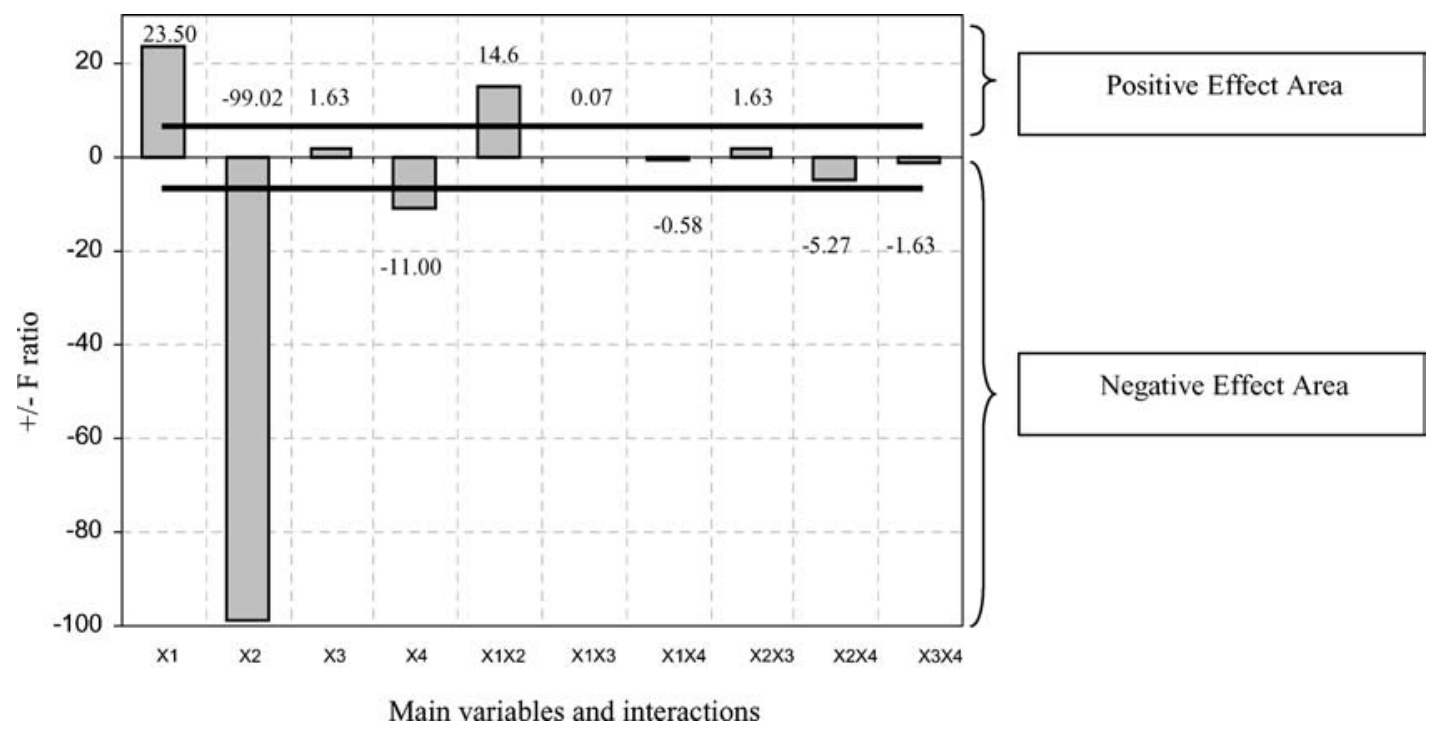

Figure 3. Results of ANOVA and Fischer-Snedecor test for $\mathrm{CeO}_{2} / \mathrm{SiO}_{2}$ factorial design. Unbroken lines represent the Fischer critical value at $95 \%$ of significance.

\subsection{Results of the ANOVA and Fischer-Snedecor Tests}

Results of ANOVA and Fischer-Snedecor tests can be interpreted using Figs. 1-3. The positive effect means that the number of fragments and/or fissures is reduced. In this case, the $F$-ratio is marked with a plus sign. The negative effect signifies an increase of observed fragments and/or fissures in sol-gel materials and the F-ratio is marked with a minus sign.

According to Fig. 1, two main factors and one interaction have a significant effect at a level of significance of $95 \%$ on cracking (fragmentation and/or fissuring) of $\mathrm{SiO}_{2}$ sol-gel materials. The two main variables are the Water:TMOS molar ratio $\left(X_{1}\right)$ and the pre-heating time $\left(X_{5}\right)$ and the interaction concerns the mixing time and the gelation time $\left(X_{3} X_{4}\right)$. The figure indicates that the Water:TMOS molar ratio and the interaction between the mixing time and the gelation time have positive effects on fissuring whereas the pre-heating time shows a negative effect. When the amount of water is increased in the sol-gel preparation, it can be observed that the number of fragments and/or fissures is reduced. Interaction between mixing time and gelation time involves an improvement in terms of cracking removal when these two variables are fixed at the same level $[(+,+)$ or $(-,-)]$. On the contrary, when the pre-heating time
$\left(X_{5}\right)$ is lengthened, fissuring and/or fragmentation of sol-gel monoliths is worsened. As the latter has a strong negative effect, it has been removed from studied variables in $\mathrm{TiO}_{2} / \mathrm{SiO}_{2}$ and $\mathrm{CeO}_{2} / \mathrm{SiO}_{2}$ statistical designs.

Effects of variables and interactions on the cracking of $\mathrm{TiO}_{2} / \mathrm{SiO}_{2}$ sol-gel materials is less visible. Only one main factor appears to be significant at a level of significance of $90 \%$ (Fig. 2). This factor is the Water:TMOS molar ratio $\left(X_{1}\right)$ and has a positive effect. Increasing the amount of water $\left(X_{1}\right.$ at the +1 level) decreases the number of fragments and/or fissures.

For $\mathrm{CeO}_{2} / \mathrm{SiO}_{2}$ factorial design, three main variables and one interaction have a significant effect on cracking (Fig. 3). The Water:TMOS molar ratio $\left(X_{1}\right)$ and the interaction between the Water:TMOS molar ratio and the $\mathrm{CeO}_{2}$ :TMOS molar ratio $\left(X_{1} X_{2}\right)$ have a positive effect whereas $\mathrm{CeO}_{2}$ :TMOS molar ratio $\left(X_{2}\right)$ and the gelation time $\left(X_{4}\right)$ have a negative effect. When the amount of water is increased in the sol-gel preparation, a better result is obtained. Interaction between the Water:TMOS molar ratio and the $\mathrm{CeO}_{2}$ :TMOS molar ratio $\left(X_{1} X_{2}\right)$ reduces cracking when the Water:TMOS molar ratio is fixed at its upper level $[(+,+)$ or $(+,-)]$. On the contrary, when the gelation time $\left(X_{4}\right)$ is lengthened and when the amount of $\mathrm{CeO}_{2}$ precursor is increased, fissuring increases. 
Table 6. BET analysis results: influence of Water:TMOS molar ratio on pore size.

\begin{tabular}{|c|c|c|c|c|c|c|}
\hline \multirow[b]{2}{*}{$\begin{array}{l}\text { Water:TMOS } \\
\text { molar ratio } \\
(\mathrm{mol} / \mathrm{mol})\end{array}$} & \multicolumn{2}{|c|}{$\mathrm{SiO}_{2}$ (Runs 1 and 2) } & \multicolumn{2}{|c|}{$\mathrm{SiO}_{2}$ (Runs 5 and 6) } & \multicolumn{2}{|c|}{$\mathrm{CeO}_{2} / \mathrm{SiO}_{2}$ (Runs 11 and 12) } \\
\hline & $\begin{array}{c}\text { mesopore } \\
\text { diameter } \\
(\AA)^{1}\end{array}$ & $\begin{array}{c}\text { micropore } \\
\text { diameter } \\
(\AA)^{2}\end{array}$ & $\begin{array}{c}\text { mesopore } \\
\text { diameter } \\
(\AA)^{1}\end{array}$ & $\begin{array}{c}\text { micropore } \\
\text { diameter } \\
(\AA)^{2}\end{array}$ & $\begin{array}{c}\text { mesopore } \\
\text { diameter } \\
(\AA)^{1}\end{array}$ & $\begin{array}{c}\text { micropore } \\
\text { diameter } \\
(\AA)^{2}\end{array}$ \\
\hline 3.8 & 25.39 & 6.45 & 29.95 & 6.34 & - & 5.62 \\
\hline 10 & 25.46 & 6.59 & 30.41 & 6.50 & - & 6.11 \\
\hline
\end{tabular}

${ }^{1} \mathrm{BJH}$ adsorption average pore diameter. Pores between 20 and $1000 \AA$ diameter.

${ }^{2}$ Horvath-Kawazoe median pore diameter.

Table 7. BET analysis results: influence of $\mathrm{CeO}_{2}$ precursor amount on pore size.

\begin{tabular}{lccc}
\hline $\begin{array}{l}\mathrm{CeO}_{2} \text { :TMOS } \\
\text { molar ratio }\end{array}$ & $\begin{array}{c}\text { BET adsorption } \\
\text { pore diameter }(\AA)\end{array}$ & $\begin{array}{c}\text { Mesopores } \\
(\AA)\end{array}$ & $\begin{array}{c}\text { Micropores } \\
(\AA)\end{array}$ \\
\hline $0.005 \%$ & 18.83 & 38.15 & 5.60 \\
$0.1 \%$ & 14.25 & $-{ }^{*}$ & 5.42 \\
\hline
\end{tabular}

* Means that there are no mesopores.

\subsection{Discussion of Significant Main Effects and Interactions Determined by the ANOVA and Fischer-Snedecor Tests}

Water:TMOS Molar Ratio $\left(X_{1}\right)$. In each case this variable reduced cracking when it was set at its upper limit $(10 \mathrm{~mol} / \mathrm{mol})$. It has been demonstrated that variations in the hydrolysis and condensation conditions profoundly affect the structures of sol-gel materials [2]. Scherer [30] and Zarzycki et al. [31] demonstrated that a maximal probability for getting a monolithic gel could be obtain by increasing the pore size of sol-gel materials. Pore size and distribution can be increased by changing the Water:TMOS molar ratio. This was assessed by performing a BET analysis (Table 6). Unfortunately, the differences in pore radius were not significant, so that the effect of water can not be attributed to reduction in capillary pressure. It is possible, therefore, that the gels made with higher water content were more permeable. A higher amount of water can also increase the connectivity of the network and thereby raise the strenght of the gel. If that is the case, the gel would have a better chance of being fissure and/or fracture free, even if the capillary pressure is unchanged. An other possibility to explain the influence of Water:TMOS molar ratio is that it might affect the amount of silicate oligomers remaining in the pores. The latter influences the viscosity of the pore liquid that plays a role in the stress generated near the end of drying.
$\mathrm{CeO}_{2}$ : TMOS Molar Ratio $\left(\mathrm{X}_{2}\right)$. This processing variable increased fissures and fragments in $\mathrm{CeO}_{2} / \mathrm{SiO}_{2}$ sol-gel materials when the amount of $\mathrm{CeO}_{2}$ precursor is increased. Contrary to Water:TMOS molar ratio effect, increasing the amount of cerium in the silica matrix leads to the formation of smaller pores. BET analysis performed on two $\mathrm{CeO}_{2} / \mathrm{SiO}_{2}$ materials having the same parameters of synthesis except for the $\mathrm{CeO}_{2}$ :TMOS molar ratio proved this phenomenon (Table 7). For the same reason as previously explained, the significant decrease in pore diameter generated by a higher amount of cerium inside the silica network explains the negative influence of the $\mathrm{CeO}_{2}$ :TMOS molar ratios on cracking of sol-gel materials.

Gelation Time $\left(\mathrm{X}_{4}\right)$. This variable corresponded to the period when the initial solution changed from a liquid to a gel and lasted until the drying step was initiated. Aging a gel before drying helps to strengthen the network and thereby reduces the risk of fragments [30]. The negative effect of the gelation time resulting from $\mathrm{CeO}_{2} / \mathrm{SiO}_{2}$ factorial design appears then difficult to interpret.

Pre-Heating Time $\left(X_{5}\right) . \quad \mathrm{SiO}_{2}$ factorial design analysis demonstrated that this parameter had a negative effect on cracking of sol-gel materials. Holding unsealed materials in an oven at $40^{\circ} \mathrm{C}$ just before the heating treatment increases the number of fragments and/or fissures in $\mathrm{SiO}_{2}$ sol-gel monoliths. Fragmentation and fissuring did not appear during the pre-heating step but was visible after the heating treatment at $500^{\circ} \mathrm{C}$. This negative effect is maximized when the gelation time and the mixing time are set at their upper limits. Preheating time occurs at the end of the drying step. The latter is composed of two stages. The first one corresponds to the evaporation of the liquid (water and solvent) at a constant velocity and to the formation of pores. During the second stage the velocity decreases 
and the pores sizes do not change any more. Then the subsequent liquid evaporation involves the creation of pores full of air [32]. If the pre-heating period occurs during the second stage of the drying process, the evaporation speed may be suddenly re-accelerated. This may involve a new contraction of the network, decreasing the pore size and leading to appearance of fragments and/or fissures. An opposite effect might have been observed if cuvettes containing $\mathrm{SiO}_{2}$ materials had been sealed during the pre-heating period.

Interaction Between Water:TMOS Molar Ratio and $\mathrm{CeO}_{2}$ :TMOS Molar Ratio $\left(\mathrm{X}_{1} \mathrm{X}_{2}\right)$. A weak interaction was found between these two terms and showed a positive effect to avoid fissuring in $\mathrm{CeO}_{2} / \mathrm{SiO}_{2}$ monoliths. It appeared that better results were obtained when Water:TMOS molar ratio was set at its upper limit $[(+,-) ;(+,+)]$. Increasing the amount of $\mathrm{CeO}_{2}$ involves a decrease in pore size of $\mathrm{CeO}_{2} / \mathrm{SiO}_{2}$ materials and results in a higher fissuring whereas a higher quantity of water introduced in the preparation acts in the opposite way. The negative effect of a higher amount of $\mathrm{CeO}_{2}$ is offset by increasing the water content.

\section{Interaction Between Mixing Time and Gelation Time}

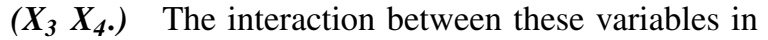
$\mathrm{SiO}_{2}$ factorial design was found to be stronger and showed a positive effect on fissure and/or fragment removal for $\mathrm{SiO}_{2}$ materials. Mixing time and gelation time have to be both at their lower and upper limits together $[(-,-) ;(+,+)]$. In $\mathrm{TiO}_{2} / \mathrm{SiO}_{2}$ and $\mathrm{CeO}_{2} / \mathrm{SiO}_{2}$ materials, this interaction was not significant. It can be assumed that mixing time and gelation time are linked to the condensation velocity of metal precursors introduced in the sol-gel syntheses.

To summarize, it has been shown that the variable having the main effect on reducing cracking in solgel materials was the amount of water introduced in the sol-gel syntheses. This parameter had to be fixed at its upper limit. Secondly, the quantity of $\mathrm{TiO}_{2}$ and $\mathrm{CeO}_{2}$ precursors were found to influence the appearance of fragments and/or fissures in a negative way. Nevertheless, this negative effect could be balanced by increasing the amount of water when the $\mathrm{TiO}_{2}$ :TMOS or $\mathrm{CeO}_{2}$ :TMOS ratios were set at their higher level. To synthesize new sol-gel materials, the Water:TMOS molar ratio has to be set at least at 10 whatever the amount of $\mathrm{TiO}_{2}$ or $\mathrm{CeO}_{2}$ precursors $\left(\mathrm{TiO}_{2}\right.$ :TMOS or $\mathrm{CeO}_{2}$ :TMOS molar ratios at $0.005 \%$ or $0.1 \%$ ). For $\mathrm{SiO}_{2}$ materials, pre-heating time showed a negative ef- fect on fissuring removal. Better results were obtained when materials were not subjected to a pre-heating treatment while unsealed. For this reason, this parameter was omitted for $\mathrm{TiO}_{2} / \mathrm{SiO}_{2}$ and $\mathrm{CeO}_{2} / \mathrm{SiO}_{2}$ factorial designs. The role of gelation time was not clearly demonstrated for all the factorial designs so that for further syntheses this parameter should be set at its lower limit. The duration of the sol-gel syntheses can then be reduced. The interaction between mixing time and gelation time appeared to be significant in the case of $\mathrm{SiO}_{2}$ sol-gel materials. The two parameters had to be set at the same level to improve cracking removal. The mixing time parameter, which was not found to be significant, will then be fixed at its lower limit in future sol-gel syntheses

\section{Conclusion}

The aim of this work was to synthesize monolithic solgel materials of $\mathrm{SiO}_{2}, \mathrm{TiO}_{2}$-doped $\mathrm{SiO}_{2}$ and $\mathrm{CeO}_{2}$ doped $\mathrm{SiO}_{2}$ showing no fragments and/or fissures in order to produce photocatalysts usable in environmental processes for water and air treatment. In this perspective, several processing variables were investigated using three $2^{4}$ statistical designs to determine their influence on the appearance of fissures and fragments into sol-gel materials. One strong critical processing variable was identified in every case: Water:TMOS molar ratio. Three other critical processing variables were also determined: pre-heating time for $\mathrm{SiO}_{2}$ statistical design, gelation time and $\mathrm{CeO}_{2}$ :TMOs molar ratio for $\mathrm{CeO}_{2} / \mathrm{SiO}_{2}$ factorial design. Two interactions terms were identified as well: Water:TMOS molar ratio with $\mathrm{CeO}_{2}$ :TMOS molar ratio and mixing time with gelation time.

Suggestions were offered that may help to explain why particular processing conditions influenced fissuring or fragmentation of sol-gel materials. The influence of variables such as the amount of water and the quantity of $\mathrm{CeO}_{2}$ or $\mathrm{TiO}_{2}$ precursors were explained according to their role on the structural characteristics of sol-gel materials. An increase of the water amount may involve larger pores and influences the permeability of the gels as well as the viscosity of the pore liquid during the drying and thus reduces the number of fragments and fissures. On the contrary, increasing the amount of $\mathrm{CeO}_{2}$ or $\mathrm{TiO}_{2}$ precursors leads to a decrease in pore size and enhances the number of fragments and/or fissures. The negative effect due to an increase of $\mathrm{TiO}_{2}$ or $\mathrm{CeO}_{2}$ precursors can be balanced by introducing a 
higher water content in the sol-gel preparation. The influence of gelation time and of its interaction with mixing time was not clearly proved. This may ensue from reproducibility problems due to the difficulty to control parameters such as temperature and relative humidity while the syntheses were carried out. Some future investigations on pore size distribution, surface area, degree of crystallinity and crystallite size could be performed to complete this work.

\section{References}

1. C. Anderson and A.J. Bard, J. Phys. Chem. 99, 9882 (1995).

2. C.J. Brinker and G.W. Scherer, Sol-Gel Science: The Physics and Chemistry of Sol-Gel Processing (Academic Press, San Diego, 1990), p. 226.

3. C. Agrafiotis, A. Tsetsekou, C.J. Stournaras, A. Julbe, L. Dalmazio, and C. Guizard, J. Eur. Ceram. Soc. 22, 15 (2002).

4. A. Trovarelli, M. Boaro, E. Rocchini, C. de Leilinburg, and G. Dolcetti, J. Alloy. and Compd. 323/324, 584 (2001).

5. M. Thammachart, V. Meeyoo, T. Risksomboon, and S. Osuwan, Catal. Today 68, 53 (2001).

6. M. Schneider and A. Baiker, Catal. Rev. Sci. Eng. 37(4), 515 (1995).

7. Y. Zhang, G. Xiong, N. Yao, W. Yang, and X. Fu, Catal. Today 68, 89 (2001).

8. J.C. Yu, J. Lin, and R.W.M. Kwok, J. Photochem. Photobio. A 111, 199 (1997)

9. M. Kang, Appl. Catal. B: Environ. 37, 187 (2002).

10. V. Héquet, C. Gonzalez, and P. Le Cloirec, Wat. Res. 35(18), 4253 (2001).

11. R.N. Viswanath, A. Chandra Bose, and J. Ramasamy, J. Phys. Chem. Solids 62, 1991 (2001).

12. T. Tulun and H. Akinci, Ceram. Int. 23, 141 (1997).

13. A. Patra, G. De, D. Kundu, and D. Ganguli, Mater. Lett. 42, 200 (2000)
14. R. Neumann and M. Levin-Elad, J. Catal. 166, 206 (1997).

15. F. Garbassi and L. Balducci, Micropor. Mesopor. Mat. 47, 51 (2001).

16. R. Reisfeld, A. Patra, G. Panczer, and M. Gaft, Opt. Mater. 13, 81 (1999).

17. E.R. Rand, M.B. Smuckler, E. Go, M.S. Bradley, and J.W. Bruno, Inorg. Chim. Acta 233, 71 (1995).

18. B. Zhu, Z. Luo, and C. Xia, Mater. Res. Bull. 34(10/11), 1507 (1999).

19. X. Gao and J.E. Wachs, Catal. Today 51, 233 (1999).

20. Z. Deng, J. Wanga, Y. Zhang, Z. Wenga, Z. Zhanga, B. Zhara, J. Shena, and L. Chenga, Nanostruct. Mater. 11, 1313 (1999).

21. A.E. Stiegman, H. Eckert, G. Plett, S.S. Kim, M. Anderson, and A. Yavrouian, Chem. Mater. 5(11), 1591 (1993).

22. M.D. Curran, D.D. Pooré, and A.E. Stiegman, Chem. Mater. 10, 3156 (1998)

23. E.P. Box, W.G. Hunter, and J.S. Hunter, Statistics for experimenters. An introduction to design, data analysis, and model building (Wiley series in probability and mathematical statistics, 1978), p. 306

24. P. Saravanan, V. Selvarajan, S.V. Joshi, and Sundararajn, J. Phys. D: Appl. Phys. 34, 131 (2001).

25. M.C. Gacula Jr. and J. Singh, Statistical Methods in Food and Consumer Research (Academic Press, Orlando, 1984), p. 62 and p. 176.

26. J.-N. Baléo, B. Bourges, P. Courcoux, C. Faur-Brasquet, and P. Le Cloirec, Méthodologie expérimentale, (Tec \& Doc, Lavoisier, Paris, 2003).

27. J. Goupy, La méthode des plans d'expériences. Optimisation du choix des essais et de l'interprétation des résultats, (DUNOD, Paris, 1996).

28. G. Sado and M.-C. Sado, Les plans d'expériences, De l'expérimentation à l'assurance qualité, (AFNOR technique, 1991).

29. W.R. Ott, Environmental Statistics and Data Analysis (Lewis Publishers, CRC Press, Boca Raton, 1995)

30. G.W. Scherer, J. Non-Cryst Solids 109, 171 (1989).

31. J. Zarzycki, M. Prassas, and J. Phalippou, J. Mater. Sci. 17, 3371 (1982).

32. R.K. Dwidevi, J. Mater. Sci. Lett. 5, 373 (1986). 